Article

\title{
Precise Measurement of Stem Diameter by Simulating the Path of Diameter Tape from Terrestrial Laser Scanning Data
}

\author{
Lei You ${ }^{1,2}$, Shouzheng Tang ${ }^{1, *}$, Xinyu Song ${ }^{3, *}$, Yuancai Lei ${ }^{1}$, Hao Zang ${ }^{1}$, Minghua Lou ${ }^{1}$ \\ and Chongyang Zhuang ${ }^{1}$ \\ 1 Institute of Forest Resources Information Techniques, Chinese Academy of Forestry, Beijing 100091, China; \\ yleiou@163.com (L.Y.); yclei@caf.ac.cn (Y.L.); b12345abba@163.com (H.Z.); mhlou1987@163.com (M.L.); \\ zhuangchongyang@126.com (C.Z.) \\ 2 College of Computer and Information Technology, Xinyang Normal University, Xinyang 464000, China \\ 3 College of Mathematics and Information Science, Xinyang Normal University, Xinyang 464000, China \\ * Correspondence: stang@caf.ac.cn (S.T.); xysong88@163.com (X.S.); \\ Tel.: +86-10-6288-8326 (S.T.); +86-37-6639-1060 (X.S.)
}

Academic Editors: Qi Chen, Guangxing Wang, Erkki Tomppo, Dengsheng Lu and Prasad S. Thenkabail Received: 27 May 2016; Accepted: 26 August 2016; Published: 31 August 2016

\begin{abstract}
Accurate measurement of stem diameter is essential to forest inventory. As a millimeter-level measuring tool, terrestrial laser scanning (TLS) has not yet reached millimeter-level accuracy in stem diameter measurements. The objective of this study is to develop an accurate method for deriving the stem diameter from TLS data. The methodology of stem diameter measurement by diameter tape was adopted. The stem cross-section at a given height along the stem was determined. Stem points for stem diameter retrieval were extracted according to the stem cross-section. Convex hull points of the extracted stem points were calculated in a projection plane. Then, a closed smooth curve was interpolated onto the convex hull points to simulate the path of the diameter tape, and stem diameter was calculated based on the length of the simulated path. The stems of different tree species with different properties were selected to verify the presented method. Compared with the field-measured diameter, the RMSE of the method was $0.0909 \mathrm{~cm}$, which satisfies the accuracy requirement for forest inventory. This study provided a method for determining the stem cross-section and an efficient and precise curve fitting method for deriving stem diameter from TLS data. The importance of the stem cross-section and convex hull points in stem diameter retrieval was demonstrated.
\end{abstract}

Keywords: stem diameter; TLS; point cloud; curve fitting; B-spline

\section{Introduction}

In recent years, retrieving forestry parameters from terrestrial laser scanning (TLS) data has become an active area of research [1,2]. As an active remote sensing technology, TLS can provide a fast and efficient tool for obtaining a dense 3D point cloud dataset containing an immense number of three-dimensional points reflected from scanned objects. Compared with airborne laser scanning and field measurements, TLS can obtain accurate understory information, including a digital record of the three-dimensional structure of forests [3]. Many studies have demonstrated the high potential of TLS in forest inventory, including tree locations [1,4-6], heights [2,3,7], diameters [2,3,6,8-15], volumes [16-18], biomass [17,19-23] and others forestry parameters [24-27]. In addition, the influence of scanner parameters on forestry parameter derivation has been studied [18,28]. Liang and Hyyppä [29] summarized the challenges of applying TLS data to forest inventories. One challenge is that the creation of forest inventory using TLS, from the forester's perspective, is a new topic. The retrieval 
of forest parameters using TLS from the forester's perspective is a precondition for the practical application of TLS data in forestry. Retrieving the stem parameter from TLS data from the forester's perspective is the focus of this study.

Among forest measurements, stem diameter has an important role in forest management. It provides basic data for the calculations of the basal area and volume and the constructions of stem curves and growth models. Accurate measurement of the stem diameter is therefore essential in forestry. Calipers and diameter tape are traditional tools for measuring the stem diameter, especially the diameter at breast height (DBH). However, these traditional measurement tools are limited in their capability to measure the diameter at multiple heights of a standing tree. TLS has the potential to obtain the three-dimensional morphological structure of a tree. On this basis, stem points can be obtained by removing branches and foliage points from tree points (Stem points refer to points that are reflected from the stem of the tree. Under the influence of occlusion, although the set of stem points may not include the entire stem, most of the stem is included in the set of stem points.). Thus, stem diameter at multiple heights, at which there is little occlusion, can be accurately extracted from the stem points.

By the definition of stem diameter, stem diameter is the diameter of the stem cross-section. Thus, the first step of retrieving the stem diameter is to locate the stem cross-section, which is perpendicular to the stem axis. This geometric constraint is satisfied when foresters measure stem diameter in the field by firmly wrapping the diameter tape around the stem [30]. However, implementing this constraint in the automatic extraction of stem diameter from TLS data is more challenging. This is because most stems have bends, twists and lumps. In other words, stems are not necessarily strictly vertical, and the stem cross-section is not necessarily parallel with the horizontal plane. This means that stem diameter cannot be simply derived by taking a slice of laser points along the horizontal plane and fitting a curve for these points. Instead, the direction of the stem axis needs to be determined first, based on which laser points surrounding the stem cross-section are extracted for stem diameter estimation.

Many studies regarding the extraction of stem diameter from terrestrial laser scanning data have been published. These studies can be divided into three categories, as listed in Table 1 . The first category is circle fitting. For example, Simonse et al. [8] mapped the scan points between 1.25 and $1.35 \mathrm{~m}$ above the terrain to a regular raster and employed the Hough transformation to detect circles in raster images. A circle fitting algorithm was subsequently employed to retrieve stem diameter. Maas et al. [9] cut a horizontal slice with a thickness of $5 \mathrm{~cm}$ at a height of $1.3 \mathrm{~m}$ above the ground. Then, a circle was fitted into the 2D projection of the points of the slice. The second category is cylinder fitting. Srinivasan [3] applied a cylinder fitting method with different height bins to retrieve the DBH for the multiple scan mode and the single scan mode. The best cylinder fitting method and the influence of the tree distance from the scanner were also investigated. The third category is the convex hull line. Gao [10] retrieved the stem diameter by calculating the circumference of a convex hull polygon for each horizontal slice.

Table 1. Overview of diameter retrieval methods using TLS and their results.

\begin{tabular}{|c|c|c|c|c|c|}
\hline Method & References & Retrieval Method & $\mathrm{Nt}^{\mathrm{a}}$ & $\mathrm{Ns}^{\mathrm{b}}$ & Result \\
\hline \multirow{6}{*}{$\begin{array}{l}\text { Circle } \\
\text { fitting }\end{array}$} & [8] & $\begin{array}{l}\text { Hough transformation for points } \\
\text { between } 1.25 \mathrm{~m} \text { and } 1.35 \mathrm{~m} \text { AGL }{ }^{\mathrm{c}} \\
\text { and circle fitting }\left(10-\mathrm{cm}^{\mathrm{thickness}}{ }^{\mathrm{d}}\right)\end{array}$ & 23 & $\begin{array}{l}\text { Multiple scans } \\
\text { (four positions) }\end{array}$ & $\mathrm{SD}^{\mathrm{e}}=2.8 \mathrm{~cm}$ \\
\hline & {$[31]$} & $\begin{array}{l}\text { Hough transformation and circle fitting } \\
\text { at } 1.3 \mathrm{~m} \mathrm{AGL}\end{array}$ & 11 & $\begin{array}{l}\text { Single scan and multiple } \\
\text { scans (four positions) }\end{array}$ & $\mathrm{NA}^{\mathrm{f}}$ \\
\hline & [2] & RANSAC algorithm for circle fitting & NA & Single scan & $\begin{array}{l}\text { RMSE }{ }^{g} \text { from } \\
2.0 \mathrm{~cm}-4.2 \mathrm{~cm}\end{array}$ \\
\hline & {$[9]$} & $\begin{array}{l}\text { Circle fitting at } 1.3 \mathrm{~m} \text { AGL } \\
\text { (5-cm thickness) }\end{array}$ & 82 & Multiple scans & $\begin{array}{l}\text { RMSE from } \\
1.8 \mathrm{~cm}-3.25 \mathrm{~cm}\end{array}$ \\
\hline & {$[13]$} & $\begin{array}{l}\text { Circle fitting at } 1.2 \mathrm{~m}, 1.3 \mathrm{~m} \\
\text { and } 1.4 \mathrm{~m} \mathrm{AGL}\end{array}$ & NA & $\begin{array}{l}\text { Single scan } \\
\text { and multiple scans }\end{array}$ & NA \\
\hline & {$[12]$} & $\begin{array}{l}\text { Hough transformation for points } \\
\text { between } 1.27 \mathrm{~m} \text { and } 1.33 \mathrm{~m} \text { AGL, circle } \\
\text { and cylinder fitting ( } 6 \text {-cm thickness) }\end{array}$ & 8 & $\begin{array}{l}\text { Multiple scans } \\
\text { (four positions) }\end{array}$ & $\begin{array}{l}\text { RMSE from } \\
1.9 \mathrm{~cm}-3.7 \mathrm{~cm}\end{array}$ \\
\hline
\end{tabular}


Table 1. Cont.

\begin{tabular}{|c|c|c|c|c|c|}
\hline Method & References & Retrieval Method & $\mathrm{Nt}^{\mathrm{a}}$ & $\mathrm{Ns}^{\mathrm{b}}$ & Result \\
\hline \multirow{7}{*}{$\begin{array}{l}\text { Cylinder } \\
\text { fitting }\end{array}$} & \multirow{5}{*}{ [3] } & $\begin{array}{l}\text { (a) Cylinder fitting 1.2-1.4 m AGL } \\
\text { (20-cm thickness) }\end{array}$ & \multirow[t]{2}{*}{20} & \multirow{2}{*}{$\begin{array}{l}\text { Multiple scans } \\
\text { (2 positions) }\end{array}$} & $R^{2}=0.95$ \\
\hline & & $\begin{array}{l}\text { (b) Cylinder fitting 1.25-1.35 m AGL } \\
\text { (10-cm thickness) }\end{array}$ & & & $R^{2}=0.91$ \\
\hline & & $\begin{array}{l}\text { (c) Cylinder fitting 1.2-1.4 m AGL } \\
\text { (20-cm thickness) }\end{array}$ & 122 & \multirow{3}{*}{ Single scan } & $\begin{aligned} R^{2} & =0.96 \\
\text { RMSE } & =2.13 \mathrm{~cm}\end{aligned}$ \\
\hline & & $\begin{array}{l}\text { (d) Cylinder fitting 1.1-1.5 m AGL } \\
\text { (40-cm thickness) }\end{array}$ & 145 & & $\begin{aligned} R^{2} & =0.97 \\
\text { RMSE } & =1.83 \mathrm{~cm}\end{aligned}$ \\
\hline & & $\begin{array}{l}\text { (e) Cylinder fitting 1.0-1.6 m AGL } \\
\text { (60-cm thickness) }\end{array}$ & 146 & & $\begin{aligned} R^{2} & =0.97 \\
\text { RMSE } & =1.85 \mathrm{~cm}\end{aligned}$ \\
\hline & [14] & $\begin{array}{l}\text { Cylinder fitting between } 1.28 \text { and } 1.32 \mathrm{~m} \\
\text { AGL and pixel method (4-cm thickness) }\end{array}$ & 199 & $\begin{array}{l}\text { Multiple scans } \\
\text { (four positions) }\end{array}$ & $R^{2}>0.946$ \\
\hline & [15] & $\begin{array}{l}\text { Cylinder fitting between } 1.25 \text { and } 1.75 \mathrm{~m} \\
\text { AGL ( } 50-\mathrm{cm} \text { thickness) }\end{array}$ & 128 & $\begin{array}{l}\text { Multiple scans } \\
\text { (five positions) }\end{array}$ & $R^{2}=0.85$ \\
\hline $\begin{array}{l}\text { Convex } \\
\text { hull line }\end{array}$ & [10] & $\begin{array}{l}\text { Convex hull line formed by } \\
\text { connecting adjacency convex } \\
\text { hull points ( } 2.5 \text {-mm thickness) }\end{array}$ & NA & Multiple scans & NA \\
\hline
\end{tabular}

According to this description, these methods have three limitations in retrieving the stem diameter: (1) the procedure for the selection of points used to extract the stem diameter was not constructed based on the stem cross-section; (2) the thickness values of the points were non-uniform and typically too large, and the points of concave bark were included in the calculation; and (3) the fitting graphics conform neither to the real shape of the stem, nor to the path of the diameter tape in the field work. Considering the irregularity of the stem and the tightness of the path of the diameter tape, some differences are observed between the stem diameters obtained using the existing TLS methods and the field-measured diameter obtained using a diameter tape. The values of the RMSE of the existing methods exceeded $1 \mathrm{~cm}$, as shown in Table 1. According to the technical standards of the Chinese national forest inventory, for a tree with a DBH of less than $20 \mathrm{~cm}$, the DBH measurement error should less than $0.3 \mathrm{~cm}$; for a tree with a DBH of more than $20 \mathrm{~cm}$, the DBH measurement error should be less than $0.015 \times \mathrm{DBH} \mathrm{cm}$. In the United States, the national forestry inventory requires a maximum DBH measurement standard deviation of $0.00255 \times \mathrm{DBH} \mathrm{cm}$ [32]. For a tree of $40 \mathrm{~cm} \mathrm{DBH}$, the measurement errors in China and the U.S. are $0.6 \mathrm{~cm}$ and $0.1 \mathrm{~cm}$, respectively. From the forester's perspective, the accuracy of the TLS-derived diameter should exceed or at least equal the measurement accuracy of a diameter tape. Obviously, the accuracy of the existing methods does not satisfy this requirement in forestry inventories. The difference between the TLS-derived diameter and field-measured diameter may be an obstacle to practical applications of TLS in forestry inventories. Consequently, the advantage of the precise measurement offered by TLS may be lost.

A forest stand is composed of individual standing trees. The accuracy of stand parameters relies on the accuracy of stem parameters for individual trees. Hence, it is necessary to investigate the accuracy level of retrieval of the stem diameter of individual trees using TLS from the forester's perspective. The objective of this study is to develop an innovative method for retrieving stem diameter at the individual tree level using TLS data from the forester's perspective and to improve the accuracy of retrieved stem diameter. The contributions of this study are as follows:

(1) Development of a method for automatically determining the stem cross-section;

(2) Development of a novel method for deriving the stem diameter by simulating the path of the diameter tape using a curve fitting method with computer graphics from TLS points; and

(3) Verification of the high accuracy of the novel method via a comparison with existing methods. 


\section{Materials and Methods}

A flowchart showing the methodology used in this study is presented in Figure 1. This section includes descriptions of the study tree species, field work and a series of procedures for simulating the path of the diameter tape to retrieve the stem diameter.

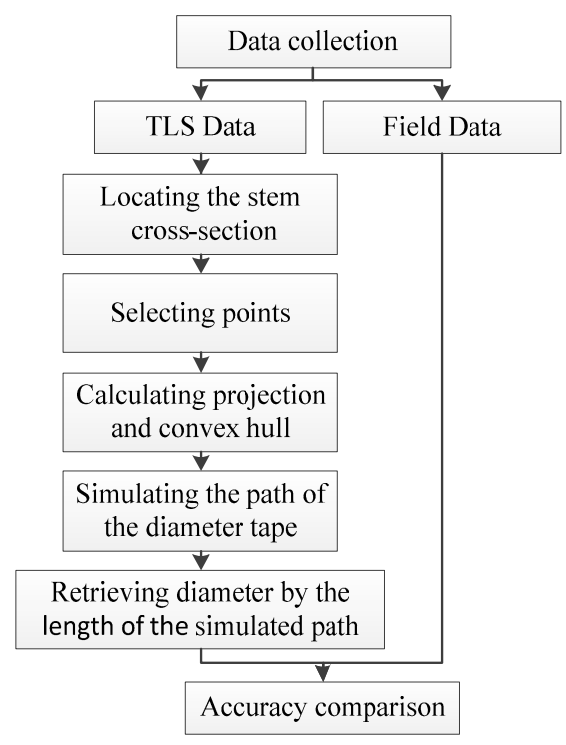

Figure 1. Flowchart of the stem diameter retrieval process.

\subsection{Study Materials}

The study area was located in the courtyard of the Chinese Academy of Forestry. The field work was completed in November 2015 and July 2016. Twelve standing trees and one log belonging to eight different tree species were chosen as the study materials. The tree information is listed in Table 2. In the field work, the stem diameter was manually measured using stainless steel diameter tape after the stem cross-section was determined. The stem cross-section can be evaluated by the perpendicularity between the path of the diameter tape and the stem axis. The path of the diameter tape was labelled with colored chalk (Figure 2). Several diameters at different height positions of the standing trees were measured. A total of 57 records of stem diameter were obtained during the field work (Table 2).

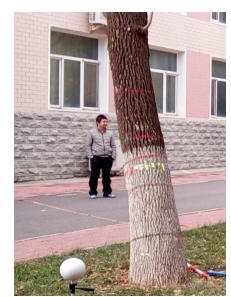

(a)

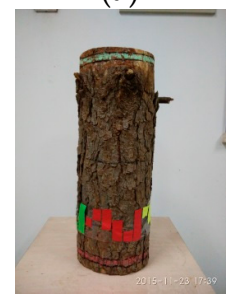

(f)

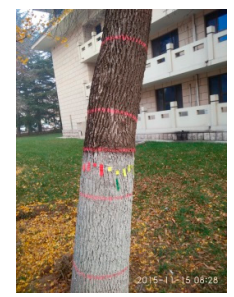

(b)

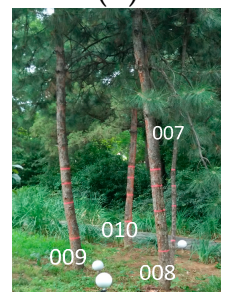

(g)

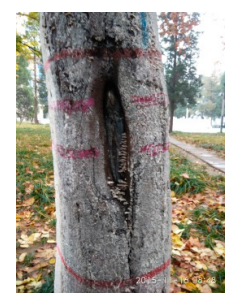

(c)

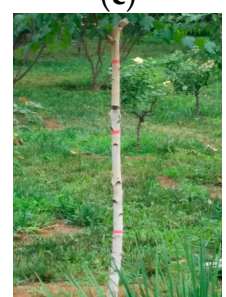

(h)

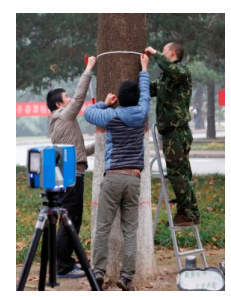

(d)

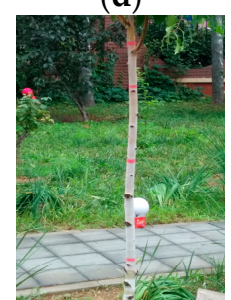

(i)

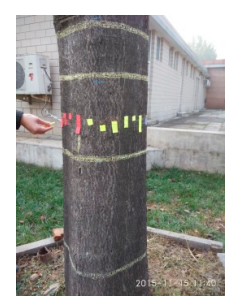

(e)

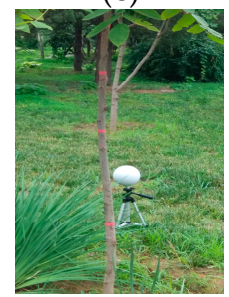

(j)

Figure 2. Field work scenes. (a) Tree 001; (b) Tree 002; (c) Tree 003; (d) Tree 004; (e) Tree 005; (f) Log 006; (g) Tree 007, Tree 008, Tree 009, and Tree 010; (h) Tree 011; (i) Tree 012; (j) Tree 013. 
Table 2. Basic information about the measured trees.

\begin{tabular}{|c|c|c|c|c|c|}
\hline ID & Tree Species & $\mathrm{DBH} / \mathrm{cm}$ & $\begin{array}{l}\text { Roughness of } \\
\text { the Stem Bark }\end{array}$ & $\begin{array}{c}\text { Number of } \\
\text { Measured Diameters }\end{array}$ & Remark \\
\hline 001 & Fraxinus pennsylvanica Marsh. & 40.4 & $\begin{array}{c}\text { Rough, } \\
\text { crowfoot cracks }\end{array}$ & 7 & The stem has a distinct tilt \\
\hline 002 & Fraxinus pennsylvanica Marsh. & 37.4 & $\begin{array}{c}\text { Rough, } \\
\text { crowfoot cracks }\end{array}$ & 6 & The stem has a distinct tilt \\
\hline 003 & $\begin{array}{l}\text { Fraxinus chinensis var. } \\
\text { rhynchophylla Hemsl. }\end{array}$ & 34.3 & $\begin{array}{l}\text { Smooth, shallow crack } \\
\text { in old bark }\end{array}$ & 7 & $\begin{array}{l}\text { A distinct concave surface } \\
\text { at the height of } 80 \mathrm{~cm}\end{array}$ \\
\hline 004 & Platanus occidentalis L. & 51.4 & Shallow ridges & 3 & \\
\hline 005 & $\begin{array}{l}\text { Ailanthus altissima } \\
\text { (Mill.) Swingle. }\end{array}$ & 37.0 & $\begin{array}{l}\text { Smooth and } \\
\text { straight grain }\end{array}$ & 6 & \\
\hline 006 & Larix gmelinii (Rupr.) Rupr. & - & Scaly & 2 & $\begin{array}{l}\text { One log; bark removed } \\
\text { from one side }\end{array}$ \\
\hline 007 & Pinus tabuliformis & 5.4 & Scaly & 4 & The stem has a distinct tilt \\
\hline 008 & Pinus tabuliformis & 11.7 & Scaly & 4 & \\
\hline 009 & Pinus tabuliformis & 12.3 & Scaly & 4 & \\
\hline 010 & Pinus tabuliformis & 10.3 & Scaly & 4 & \\
\hline 011 & Populus tomentosa Carr & 3.0 & Smooth & 3 & \\
\hline 012 & Populus tomentosa Carr & 3.0 & Smooth & 4 & \\
\hline 013 & Juglans regia & 2.7 & Rough & 3 & \\
\hline
\end{tabular}

Four-directional scans of each tree were conducted using a FARO X330 terrestrial laser scanner. The scan quality was $4 \times$; the scan resolution was $\frac{1}{4}$; the scan speed was $122 \mathrm{kpts} / \mathrm{s}$ (122 thousands points per second); and the point distance was $6.136 \mathrm{~mm} / 10 \mathrm{~m}$ (the point distance describes the scan accuracy and refers to the distance between the two nearest captured scan points in $\mathrm{mm}$ at a scan distance of $10 \mathrm{~m}$ ). For each standing tree, the horizontal distances from the tree to the scanner in different scan positions were between 8 and $10 \mathrm{~m}$, and the distance from the scanner to the log was approximately $2.5 \mathrm{~m}$ (it was scanned in the room). The scanner was placed on the tripod, and the height of the scanner was approximately $1.2 \mathrm{~m}$. The point cloud registration of the four scans and the extraction of the tree stem points were manually performed using the FARO Scene5.0 software.

\subsection{Determining the Stem Cross-Section}

The stem cross-section is the intersection between a plane and the tree stem. It should be perpendicular to the stem axis. For simplification, the plane of the stem cross-section is referred to as the stem cross-sectional plane.

A stem does not have a regular geometry. Different stem cross-sections at different heights are not parallel. The stem cross-sectional planes at different heights along the stem should be determined individually. In this study, the stem cross-sectional plane at a given height $h$ was determined by an anchor point and the growth direction of the stem at the given height. First, an anchor point $P$ on the stem cross-section was located according to the height value $h$ and the given initial normal vector $\widehat{n}_{0}(0,0,1)$. Second, the applicable normal vector $\widehat{n}$ of the stem cross-section, which was equal to the growth direction of the stem, was calculated by iteration. Third, the stem cross-sectional plane was determined by the normal vector $\widehat{n}$ and the anchor point $P$.

\subsubsection{Locating the Anchor Point of the Stem Cross-Section}

The stem diameter usually refers to the diameter of the stem cross-section at a certain height along the stem. Given the irregular geometry of a stem, the different points on the same stem cross-section may have different height values. In this study, the height value of the stem was the vertical distance from the lowest point to the geometrical central point of the stem. The lowest point can be calculated from the stem points. An initial plane (Figure 3) can be calculated based on the initial normal vector $\widehat{n}_{0}$, the lowest point and the height value $h$. An upper plane was constructed above and parallel to the initial plane. The distance between the planes was $0.5 \mathrm{~cm}$. Then, a stem slice was formed between the two planes. The anchor point (Figure 3) was the geometric central point of the stem slices. 


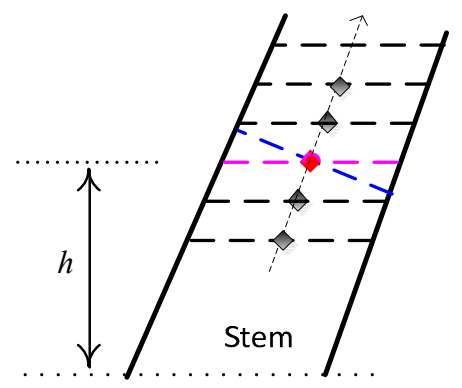

Figure 3. Diagram representing the method for the determination of a stem cross-sectional plane at a given height. The red point represents the anchor point. The pink dashed line represents the initial plane. The blue dashed line represents the stem cross-section corresponding to the anchor point. The direction of the arrow represents the growth direction of the stem at height $h$. Two adjacent stem cross-sections form a stem slice.

The irregularity of the stem cross-section yields a complicated geometrical shape of the stem slice. Additionally, the density of the stem points is uneven, and a stem may have concave surfaces. Considering the above factors, it is a challenge to accurately define the geometric central point of a stem slice. In this study, the geometric central point of a stem slice was represented by the centroid of the convex polygon that was formed from the planar projection point set, which is the resultant point set of the stem slice points projecting onto its lower stem cross-section.

\subsubsection{Calculating the Growth Direction of the Stem}

According to the above method of obtaining a stem slice, the other four stem slices can be obtained using parallel planes (Figure 3). Two of the four stem slices was above the stem slice of the anchor point, and the other two planes were below the stem slice of the anchor point. Then, five geometric central points of the stem slices can be calculated. The growth direction of the stem is approximately equal to the maximum variation direction of the geometric central points of the stem slices. Then, the principal component analysis (PCA) method was used to calculate the growth direction. The eigenvector that corresponds to the greatest eigenvalue is the growth direction of the stem.

Obviously, the more parallel the relationship between the plane of the stem slice and the stem cross-section of the stem, the more accurate the derived growth direction. Hence, an iterative strategy was adopted. The $i$-th iteration is described as follows: the geometric central point $Q_{i}$ of the stem slices was calculated from the previous normal vector $\hat{n}_{i-1}$. The normal value $\hat{n}_{i}$ was calculated from PCA and $Q_{i}$. The iteration ended when the included angle $\theta_{i-1}$ between $\hat{n}_{i-1}$ and $\hat{n}_{i}$ was less than 0.5 degrees or the absolute difference between the adjacent included angles $\theta_{i-1}$ and $\theta_{i}$ was less than 0.5 degrees. Then, $\hat{n}_{i}$ was the growth direction of the stem at the given height and the applicable normal vector $\widehat{n}$ of the stem cross-section. Note that points of the stem slices may be changed during each iteration. The lower stem cross-section of the third stem slice in each iteration must pass through the anchor point to ensure the validity of the iteration (Figure 3).

\subsection{Selecting Points for Retrieving Stem Diameter}

The point set that is used to retrieve stem diameter is denoted by $P$. The point set $P$ can be selected after the stem cross-section is located. The point set $P$ should be sourced from points of the stem cross-section. Because the distances from a target tree to the scanner are different in different scanner positions, the distribution of stem points is uneven. The points belonging only to a certain stem cross-section do not reflect the integral profile of the stem cross-section. Additionally, the path of the diameter tape has a constant width, which is equal to the width of the diameter tape. Thus, the point set $P$ can be selected from a band of stem points between two parallel stem cross-sectional planes. The normal vectors of the two parallel stem cross-sectional planes are equal, and the distance between the two parallel stem cross-sectional planes is the width of the diameter tape. To avoid confusion, 
the thickness of the stem points used for extracting stem diameter was the distance between the two parallel stem cross-sectional planes and was referred to as the width of the band in this study.

In experiments of this study, for compatibility and comparison with the field-measured diameter in the field work, the point set $P$ should represent the colored points that consist only of the points on the path of the diameter tape. According to Section 2.2, the normal vector of the two parallel stem cross-sectional planes can be calculated, and the distance between the two parallel stem cross-sectional planes is equal to $1 \mathrm{~cm}$, which is the width of the diameter tape. Then, the path of the diameter tape in the field work traces the area between the two parallel stem cross-sectional planes in the stem. The selected points of one path of the diameter tape of Tree 002 and Tree 003 are shown in Figure 4.

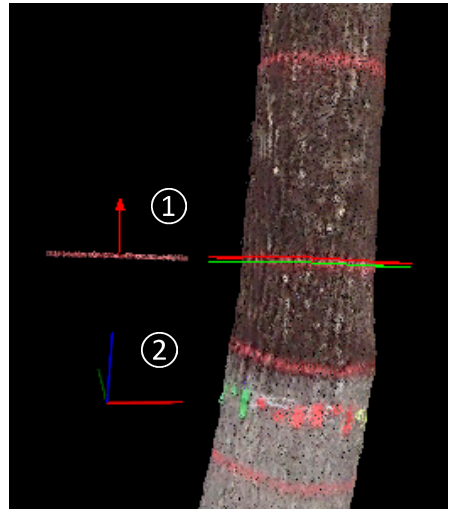

(a)

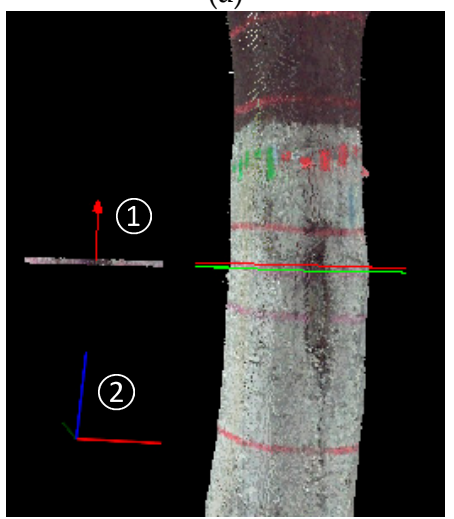

(c)

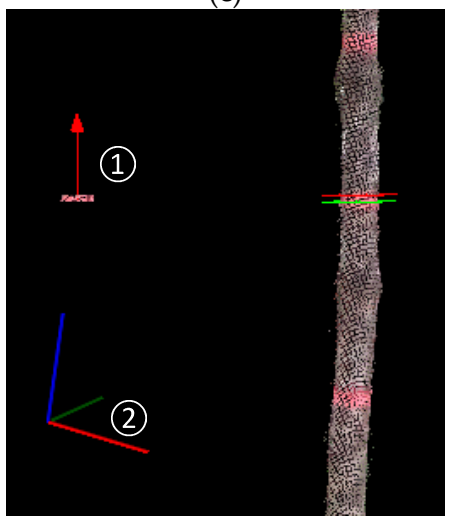

(e)

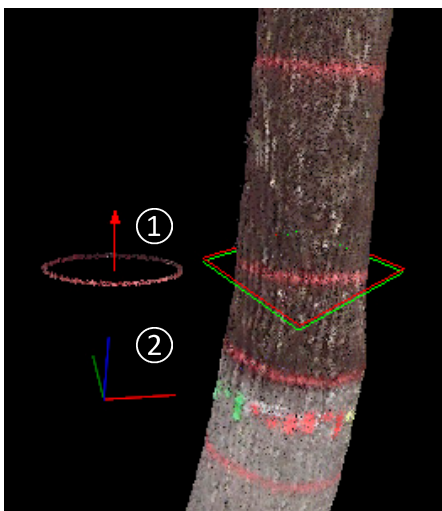

(b)

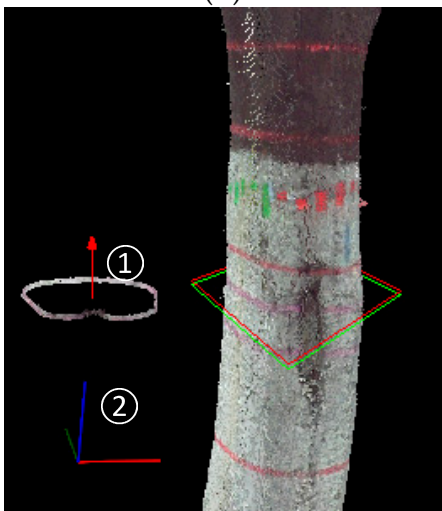

(d)

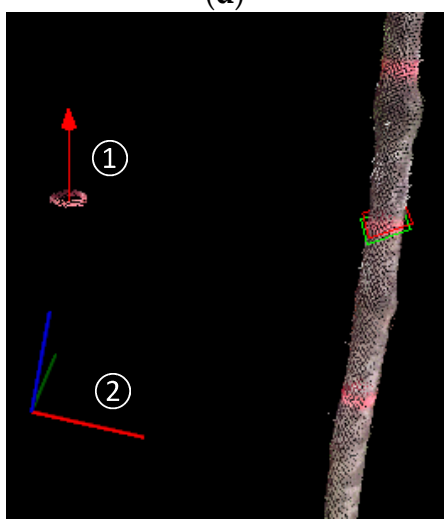

(f)

Figure 4. Stem cross-sectional planes of trees. (a) Front view of Tree 002; (b) side view of Tree 002; (c) front view of Tree 003; (d) side view of Tree 003; (e) front view of Tree 007; (f) side view of Tree 007. (1) represents a copy of the stem cross-sectional points, and (2) represents the coordinate axis. The red arrow represents the normal vector of the stem cross-sectional plane. The red rectangle represents the upper stem cross-sectional plane. The green rectangle represents the lower stem cross-sectional plane. The length of the coordinate axis is $20 \mathrm{~cm}$. 


\subsection{Calculating the Projection and the Convex Hull}

The thickness value of the stem points for calculating the stem diameter is the width value of the diameter tape. Direct simulation of the path of the diameter tape in three-dimensional space is difficult. However, the path of the diameter tape can be simplified as a closed curve. Then, the problem of simulating the path of the diameter tape can be considered as a problem of curve fitting. The path of the diameter tape is formed by the bulgy bark of the stem. The simulation path of the diameter tape should also adhere to this notion. The convex hull of the point set $X$ is the smallest convex set that contains $X$. The bulgy bark of the stem can be considered to be the convex hull of the stem points. For more information about the convex hull, please refer to [33].

In Section 2.3, the point set $P$ that is used to calculate stem diameter was selected through two stem cross-sectional planes. Note that point set $P$ is a point set in three-dimensional space. The planar point set $P_{\text {projection }}$ was obtained by projecting point set $P$ onto one of the two stem cross-sectional planes. Then, the convex hull points of the planar point set $P_{\text {projection }}$ served as the interpolation points that were used for curve fitting to simulate the path of the diameter tape. The planar point set $P_{\text {projection }}$ is also a point set in three-dimensional space. To simplify the computation, the point set $P_{\text {projection }}$ can be converted to a planar point set $P^{\prime}$ in two-dimensional space by point rotating. Then, a simulated path of the diameter tape can be interpolated on the convex hull points of the planar point set $P^{\prime}$ in two-dimensional space. The convex hull points of the stem cross-section of Figure 3 are shown in Figure 5.

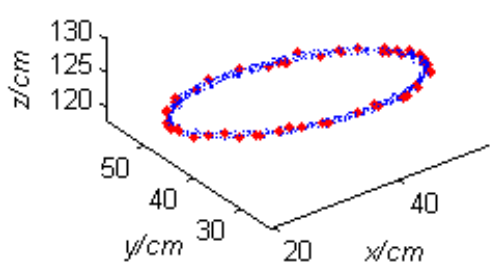

(a)

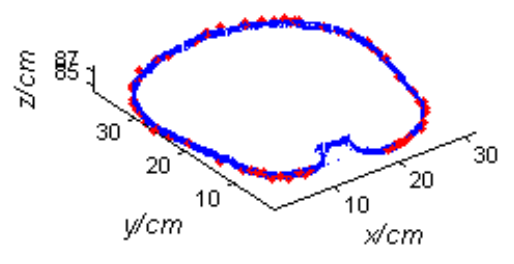

(c)

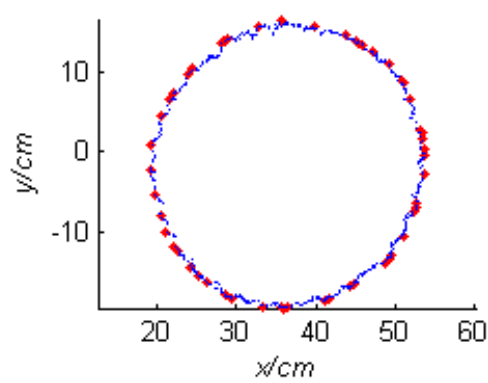

(b)

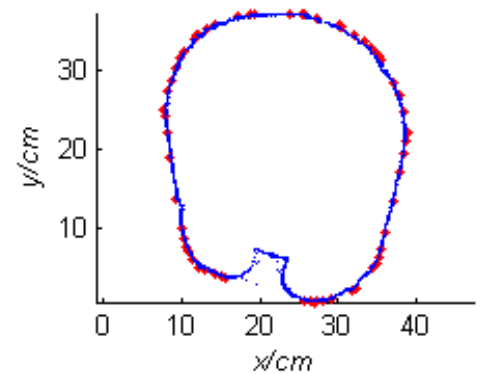

(d)

Figure 5. Stem cross-sectional points for the simulated path of the diameter tape. (a) Stem cross-sectional points of Tree 002; (b) planar projection point set of the stem cross-sectional points in (a); (c) stem cross-sectional points of Tree 003; (d) planar projection point set of the cross-sectional points in (c). The red points represent the convex hull points calculated from the planar projection point set.

\subsection{Simulating the Path of the Diameter Tape}

The problem of simulating the path of the diameter tape can be described as follows: for a given convex hull point set $P_{\text {hull }}$ of the projected points in a two-dimensional space, a smooth closed curve, which passes through the points of $P_{\text {hull }}$, can be constructed. This problem is a classic problem in computer graphics. A B-spline curve is a common method for curve fitting due to its superior properties. A cubic B-spline curve is a second-order geometric continuity curve; the path of the 
diameter tape also has the property of second-order geometric continuity. Thus, a closed smooth cubic non-rational B-spline curve was employed to simulate the path of the diameter tape in this study.

Three steps are required to construct a $p$-th non-rational B-spline curve to interpolate the points in $\left\{q_{k}\right\}, k=0, \ldots, n$. The first step is to assign the parameter value $\bar{u}_{k}$ for each $q_{k}$. The construction of an appropriate non-decreasing knot vector $U=\left\{u_{0}, \ldots, u_{m}\right\}$ is the second step. Setting up and resolving the $(n+1) \times(n+1)$ system of linear equations is the third step. The linear equations can be described as:

$$
q_{k}=C\left(\bar{u}_{k}\right)=\sum_{i=0}^{n} N_{i, p}\left(\bar{u}_{k}\right) P_{i}
$$

where the control points $P_{i}$ are the $n+1$ unknown points, $p$ is the degree of B-spline curve and $N_{i, p}(u)$ is the $i$-th of $p$-degree B-spline basis function. In this study, a recurrence formula presented by deBoor, Cox and Mansfield [34] is employed as the B-spline basis function. $N_{i, p}(u)$ is defined as:

$$
\begin{aligned}
& N_{i, 0}(u)=\left\{\begin{array}{l}
1, u_{i} \leq u \leq u_{i+1} \\
0, \text { otherwise }
\end{array}\right. \\
& N_{i, p}(u)=\frac{u-u_{i}}{u_{i+p}-u_{i}} N_{i, p-1}(u)+\frac{u_{i+p+1}-u}{u_{i+p+1}-u_{i+1}} N_{i+1, p-1}(u)
\end{aligned}
$$

where $u_{i} \in U, u_{i} \leq u_{i+1}$.

After the three steps, the $p$-th non-rational B-spline curve can be defined by:

$$
C(u)=\sum_{i=0}^{n} N_{i, p}(u) P_{i}, u_{0} \leq u \leq u_{m}
$$

The results of the $\bar{u}_{k}$ and knot vector $U$ affect the shape and parameterization of the curve. Based on the experiment, the centripetal method [35] for assigning the parameter value $\bar{u}_{k}$ for $q_{k}$ and the averaging method [34] for constructing the knot vector $U$ were employed in this study.

The centripetal method is described as follows: Let:

$$
d=\sum_{k=1}^{n} \sqrt{\left|q_{k}-q_{k-1}\right|}
$$

Then, the parameter value:

$$
\bar{u}_{0}=0, \bar{u}_{n}=1, \bar{u}_{k}=\bar{u}_{k-1}+\sqrt{\left|q_{k}-q_{k-1}\right|} / d, k=1,2, \ldots, n-1
$$

The averaging method [34] for constructing the knot vector $U$ can be defined by:

$$
u_{0}=\ldots=u_{p}=0, u_{m-p}=\ldots=u_{m}=1, u_{j+p}=\frac{1}{p} \sum_{i=j}^{j+p-1} \bar{u}_{i}, j=1,2, \ldots, n-p
$$

When $p=3$, a cubic non-rational B-spline curve that passes through the given points $\left\{q_{k}\right\}$ can be constructed. To construct a closed smooth cubic non-rational B-spline curve, the first point of $\left\{q_{k}\right\}$ is established as the landmark point. The first three points of $\left\{q_{k}\right\}$ are inserted at the rear of $\left\{q_{k}\right\}$, whereas the last three points of $\left\{q_{k}\right\}$ are inserted at the head of $\left\{q_{k}\right\}$. Then, a new point set $\left\{q_{k}\right\}$ is formed. The interpolating curve of the new $\left\{q_{k}\right\}$ will pass through the landmark point twice. The parameter values $u_{\text {start }}$ and $u_{\text {end }}$ are noted when the curve passes through the landmark point. A closed smooth curve will be obtained according to Formula (4) by replacing $u_{0}$ and $u_{1}$ with $u_{\text {start }}$ and $u_{\text {end }}$.

The simulated paths of the diameter tape are shown in Figure 6 . Figure $6 a, b$ corresponds to the stem cross-section in Figure 5a,c. Figure 6c shows a simulated path of the diameter tape for Tree 005. 

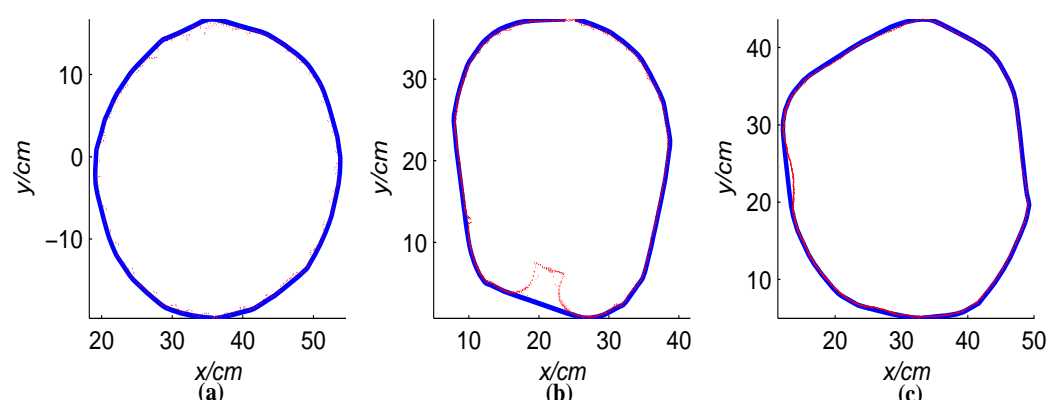

Figure 6. Stem cross-sectional points for the simulation path of the diameter tape. The red points are the original stem points. The blue curve is the closed smooth curve of the simulated path of the diameter tape. (a) the simulated path of the stem cross-sectional of Figure 5a; (b) the simulated path of the stem cross-sectional of Figure 5c; (c) the simulated path of the stem cross-sectional of tree 005 at a height of $1 \mathrm{~m}$.

As shown in Figure 6, the simulated path of the diameter tape was tightly wrapped around the outer points of the stem cross-section, and the concave region was overlooked. This condition conforms to the situation of stem diameter that was measured by the diameter tape in the field work.

\subsection{Retrieving Stem Diameter}

Stem diameter can be retrieved by the length of a closed smooth curve.

$$
D=L / \pi
$$

where $L$ is the length of the closed smooth curve and $D$ is the diameter value of the stem cross-section. In this study, the closed smooth curve is created by a cubic B-spline curve that is defined by several piecewise polynomial curves. Each section is a cubic polynomial curve. The length of each section can be solved by integrating. The formula of $C(u)$ can be rewritten as:

$$
C(u)=\left\{\begin{array}{l}
x_{i}=x(u) \\
y_{i}=y(u) \\
z_{i}=z(u)
\end{array}\right.
$$

The length $s^{\prime}$ of the curve that extends between the parameter value $u=\alpha$ and $u=\beta$ can be solved by:

$$
s^{\prime}=\int_{\alpha}^{\beta} f(u) d u=\int_{\alpha}^{\beta} \sqrt{x^{\prime}(u)^{2}+y^{\prime}(u)^{2}+z^{\prime}(u)^{2}} d u
$$

In this study, $x(u), y(u)$ and $z(u)$ are cubic polynomials. Thus, the primitive function of $f(u)$ does not have an explicit solution. Thus, the length value of $s^{\prime}$ cannot be directly calculated. However, it can be indirectly calculated by the numerical integration of the composite Simpson's rule. Please refer to the books about numerical integration to learn about the composite Simpson's rule.

The implementation of the method presented in this study was based on the Point Cloud Library (PCL) [36]. PCL is a standalone, large-scale, open source $\mathrm{C}++$ library for 2D/3D image and point cloud processing.

\section{Results}

\subsection{The Accuracy of Determining the Stem Cross-Section}

As shown in Figure 4, after the stem cross-sectional plane was determined from the height, the two parallel planes were constructed. The lower one is the stem cross-sectional plane, and the distance 
between the planes is equal to the width of the diameter tape. The colored points labelled in the field work lie exactly between the two planes. The shown color of the copy stem cross-sectional points is similar to the tracing of the colored chalk. Thus, the stem points between the two planes were the points through which the path of the diameter tape passed. The accuracy of the stem cross-section location method was demonstrated.

\subsection{Comparison with Existing Methods}

As described in Table 1, circle fitting, cylinder fitting and the convex hull line are used in the main calculation method used to retrieve stem diameter. The similarity between circle fitting and cylinder fitting is that the stem cross-section is treated as a regular circle. The computational processes of circle fitting and the convex hull line methods were applied to the plane as in the computational processes used in this study. Thus, circle fitting and the convex hull line were chosen for comparison with the method presented in this study.

The data for circle fitting are the planar point set $P^{\prime}$ described in Section 2.4. The data for the convex hull line and the simulated path of the diameter tape by the cubic B-spline curve are the convex hull points of $P^{\prime}$, which are also described in Section 2.4.

According to Section 2, the stem cross-sectional points, which correspond to the path of the diameter tape from the field work, were obtained. The diameters manually measured in the field work and retrieved from stem cross-sectional points are listed in Table 3.

Table 3. Diameter values calculated using different methods.

\begin{tabular}{|c|c|c|c|c|c|}
\hline ID & Height/m & $D / c m$ & $D_{s} / \mathrm{cm}$ & $D_{c l} / \mathrm{cm}$ & $D_{c} / \mathrm{cm}$ \\
\hline 001 & 0.50 & 46.6 & 46.2415 & 46.1924 & 45.1921 \\
\hline 001 & 1.00 & 42.2 & 41.8757 & 41.8143 & 40.7584 \\
\hline 001 & 1.30 & 40.4 & 40.3620 & 40.3822 & 39.2691 \\
\hline 001 & 1.50 & 39.7 & 39.5651 & 39.5358 & 38.7012 \\
\hline 001 & 2.00 & 37.7 & 37.7176 & 37.7144 & 36.5806 \\
\hline 001 & 3.00 & 35.9 & 35.6431 & 35.6399 & 34.5405 \\
\hline 001 & 4.00 & 37.4 & 37.6119 & 37.5250 & 35.6792 \\
\hline 002 & 0.50 & 40.4 & 40.2163 & 40.1856 & 39.4718 \\
\hline 002 & 1.00 & 38.4 & 38.1978 & 38.1654 & 37.5773 \\
\hline 002 & 1.30 & 37.4 & 37.3334 & 37.2891 & 36.5253 \\
\hline 002 & 1.50 & 35.35 & 35.2179 & 35.1855 & 34.5931 \\
\hline 002 & 2.00 & 33.8 & 33.6525 & 33.6007 & 32.8179 \\
\hline 002 & 3.00 & 33.25 & 33.2248 & 33.1830 & 32.4895 \\
\hline 003 & 0.50 & 34.7 & 34.5273 & 34.5049 & 33.9276 \\
\hline 003 & 0.80 & 34.8 & 34.8231 & 34.8553 & 33.4481 \\
\hline 003 & 0.90 & 34.9 & 34.7670 & 34.7509 & 33.5247 \\
\hline 003 & 1.00 & 34.8 & 34.8207 & 34.7803 & 33.8948 \\
\hline 003 & 1.30 & 34.3 & 34.2022 & 34.1576 & 33.0610 \\
\hline 003 & 1.50 & 35.2 & 35.3680 & 35.3875 & 33.9567 \\
\hline 003 & 2.00 & 30.4 & 30.3993 & 30.4334 & 29.4706 \\
\hline 004 & 0.70 & 57.5 & 57.3449 & 57.3169 & 56.6919 \\
\hline 004 & 1.30 & 51.4 & 51.2727 & 51.2322 & 50.6099 \\
\hline 004 & 2.00 & 48.8 & 48.6502 & 48.6646 & 48.0717 \\
\hline 005 & 0.50 & 43.0 & 42.7024 & 42.6791 & 41.8089 \\
\hline 005 & 1.00 & 38.4 & 38.2160 & 38.2974 & 37.5228 \\
\hline 005 & 1.30 & 37.0 & 36.8702 & 36.9011 & 36.2505 \\
\hline 005 & 1.50 & 37.0 & 37.3557 & 37.2940 & 36.2504 \\
\hline 005 & 2.00 & 35.5 & 35.5000 & 35.4729 & 34.8375 \\
\hline 005 & 3.00 & 35.15 & 35.3109 & 35.2700 & 34.2505 \\
\hline 006 & - & 16.4 & 16.3878 & 16.3763 & 16.2148 \\
\hline 006 & - & 17.7 & 17.7304 & 17.7303 & 17.2692 \\
\hline 007 & 0.50 & 5.9 & 5.9466 & 5.9534 & 5.7052 \\
\hline 007 & 1.00 & 5.6 & 5.4879 & 5.5806 & 5.3767 \\
\hline
\end{tabular}


Table 3. Cont.

\begin{tabular}{cccccc}
\hline ID & Height/m & $D / \mathbf{c m}$ & $D_{s} / \mathbf{c m}$ & $D_{c l} / \mathbf{c m}$ & $D_{c} / \mathbf{c m}$ \\
\hline 007 & 1.30 & 5.4 & 5.4071 & 5.4385 & 5.1792 \\
007 & 1.50 & 5.3 & 5.1603 & 5.2300 & 4.9657 \\
008 & 0.50 & 12.3 & 12.3174 & 12.3152 & 12.0399 \\
008 & 1.00 & 12.0 & 12.0731 & 12.0331 & 11.6068 \\
008 & 1.30 & 11.7 & 11.7494 & 11.7880 & 11.3749 \\
008 & 1.50 & 11.3 & 11.4117 & 11.3875 & 11.0246 \\
009 & 0.50 & 13.0 & 12.8618 & 12.9073 & 12.6933 \\
009 & 1.00 & 12.4 & 12.4670 & 12.4317 & 12.0810 \\
009 & 1.30 & 12.3 & 12.2817 & 12.2963 & 11.9713 \\
009 & 1.50 & 12.1 & 12.4129 & 12.3310 & 11.7435 \\
010 & 0.50 & 11.3 & 11.4534 & 11.4542 & 11.0687 \\
010 & 1.00 & 10.3 & 10.1848 & 10.3085 & 9.9681 \\
010 & 1.30 & 10.3 & 10.2484 & 10.3666 & 9.9732 \\
010 & 1.50 & 10.2 & 10.4988 & 10.4891 & 10.1599 \\
011 & 0.50 & 3.7 & 3.8777 & 3.8761 & 3.5377 \\
011 & 1.00 & 3.4 & 3.5540 & 3.5918 & 3.3243 \\
011 & 1.30 & 3.0 & 3.1254 & 3.1061 & 2.8574 \\
012 & 0.50 & 3.7 & 3.7272 & 3.6921 & 3.4209 \\
012 & 1.00 & 3.2 & 3.4055 & 3.3502 & 2.9260 \\
012 & 1.30 & 3.0 & 3.1859 & 3.1778 & 2.6804 \\
012 & 1.50 & 3.0 & 3.1570 & 3.2102 & 2.7429 \\
013 & 0.50 & 3.5 & 3.7953 & 3.8336 & 3.4315 \\
013 & 1.00 & 2.9 & 3.0632 & 3.0180 & 2.7366 \\
013 & 1.30 & 2.7 & 2.7876 & 2.9048 & 2.3761 \\
\hline
\end{tabular}

ID is the temporary tree identifier; height is the height of the measurement on the standing tree; $D$ is the field-measured diameter; $D_{s}$ is the diameter retrieved by simulating the path curve of the diameter tape using a cubic B-spline; $D_{c l}$ is the diameter retrieved using the convex hull line method; and $D_{c}$ is the diameter retrieved using circle fitting. Stem 006 is a log; its height was not measured.

The differences in the diameter between the field-measured diameters and the diameters retrieved from the stem points are shown in Figure 7.

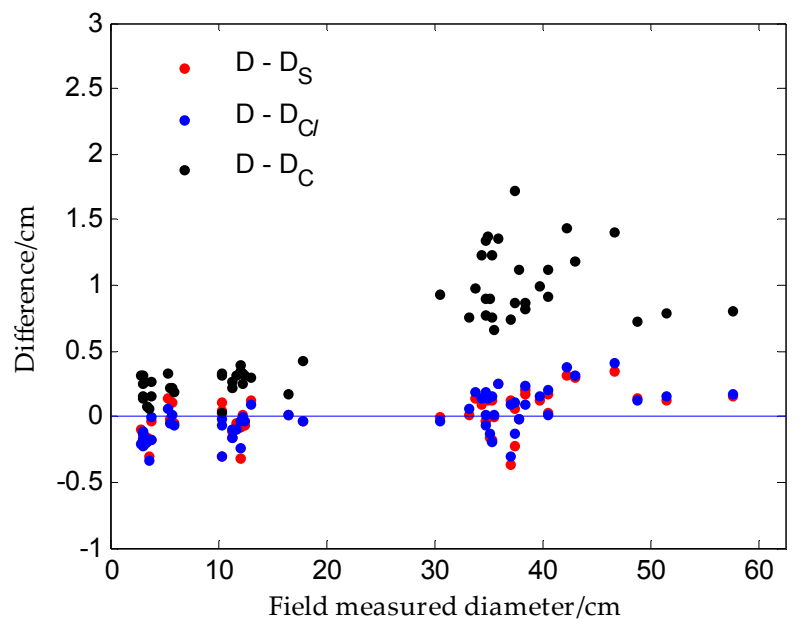

Figure 7. Differences between the field-measured diameters and diameters retrieved from stem points.

Figure 7 depicts the differences between the field-measured diameters and the retrieved diameters. The diameter derived from circle fitting has the largest error compared with the diameter derived from the convex hull line and the simulated path of the diameter tape by the cubic B-spline curve. The best results are obtained from the path simulated by the B-spline curve. Note that the differences between the field-measured diameters and simulated path were not influenced by the diameter. Figure 7 also 
demonstrated that the greater the diameter, the greater the error in the circle fitting method. When the stem diameter is larger, the shape of the stem cross-section is more complex, and the stem bark is rougher. Hence, the errors in the circle fitting method are bigger.

Assuming that the field measurement is an unbiased estimate of the diameter, a linear relationship between the diameter derived from TLS and the diameter measured in the field work can be established. The regression equation can be defined as follows:

$$
\hat{D}_{i}=a \times D_{i}+b
$$

According to the relationship between the diameter derived from TLS $\hat{D}_{i}$ and the diameter measured in the field work $D_{i}$, the value of $a$ is close to one, and the accuracy of the derived diameter method is high; at the same value of $a$, the value of $b$ is close to zero, and the accuracy of the derived diameter method is high.

The results of the regressions between the field-measured diameters and the TLS-derived diameters obtained using three different methods are shown in Figure 8. The regression parameter $a$ of the simulated path with the B-spline curve was the best parameter and was near one. The RMSE value and the $R^{2}$ value of simulated path with the B-spline curve were also optimal values. The RMSE value of the method was less than one eighth the value of the circle fitting method. The formulas for RMSE, $R^{2}$, MAE (mean absolute error) and MAPE (mean absolute percentage error) are shown below.

$$
\begin{gathered}
R M S E=\sqrt{\frac{1}{n} \sum_{i=1}^{n}\left(D_{i}-\hat{D}_{i}\right)^{2}} \\
R^{2}=\frac{\sum_{i=1}^{n}\left(\hat{D}_{i}-\bar{D}\right)^{2}}{\sum_{i=1}^{n}\left(D_{i}-\bar{D}\right)^{2}} \\
M A E=\frac{1}{n} \sum_{i=1}^{n}\left|D_{i}-\hat{D}_{i}\right| \\
M A P E=100 \times \frac{1}{n} \sum_{i=1}^{n}\left|D_{i}-\hat{D}_{i}\right| / D_{i}
\end{gathered}
$$
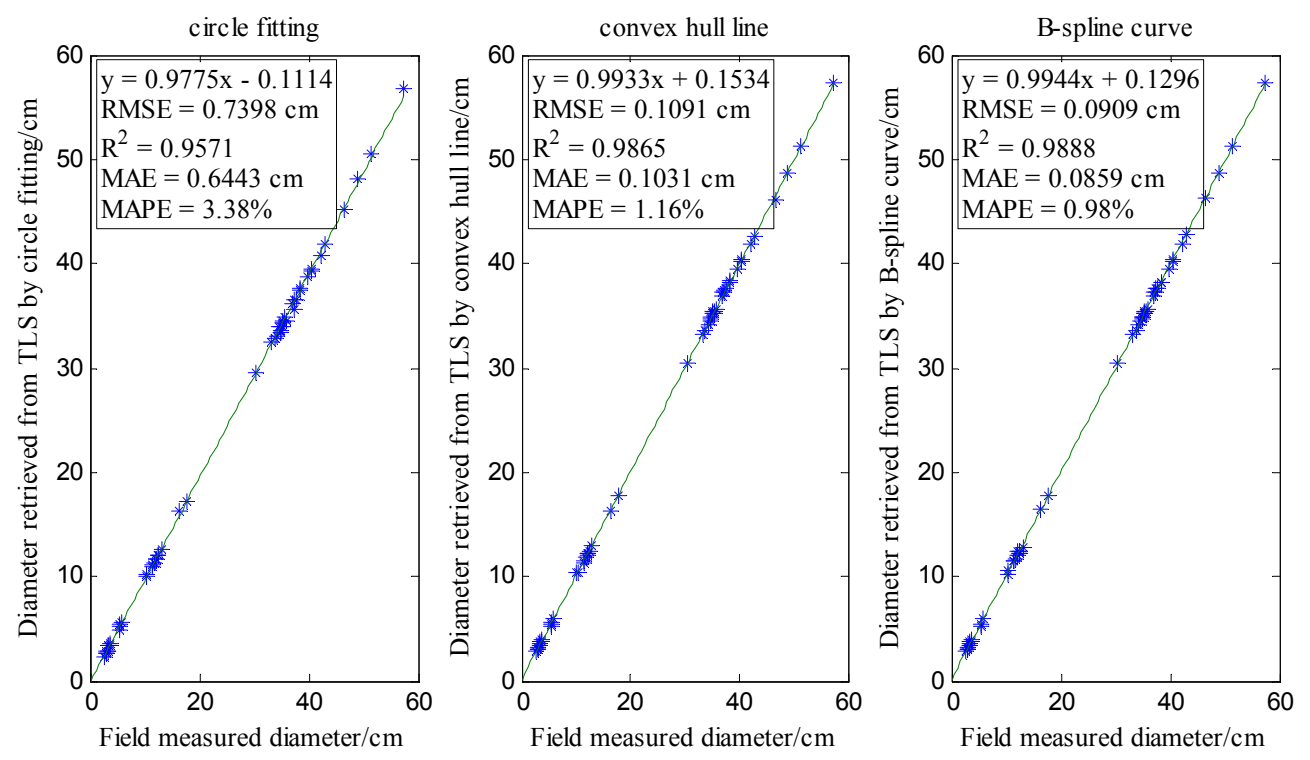

Figure 8. The results of the regressions between the field-measured diameters and the TLS-derived diameters. 
In this study, the maximum and minimum heights of the stem were 4.00 and $0.50 \mathrm{~m}$, respectively. The relationship of stem height to the diameter difference (Figure 9) indicated that the difference in diameter between the field-measured diameters and the diameters retrieved from the stem points did not increase with increased stem height. The maximum diameter difference at different heights did not exceed $0.5 \mathrm{~cm}$. The shapes of the stem cross-section also differed, as shown in Figure 6. Compared with the field-measured diameters, the RMSE value of the diameter derived from simulating the path using the cubic B-spline curve was $0.0909 \mathrm{~cm}$. According to the technical standards of the national forest inventory in China and the U.S., the results suggest that the stem diameters derived from simulating the path using the cubic B-spline curve are satisfactory and have potential for general applicability.

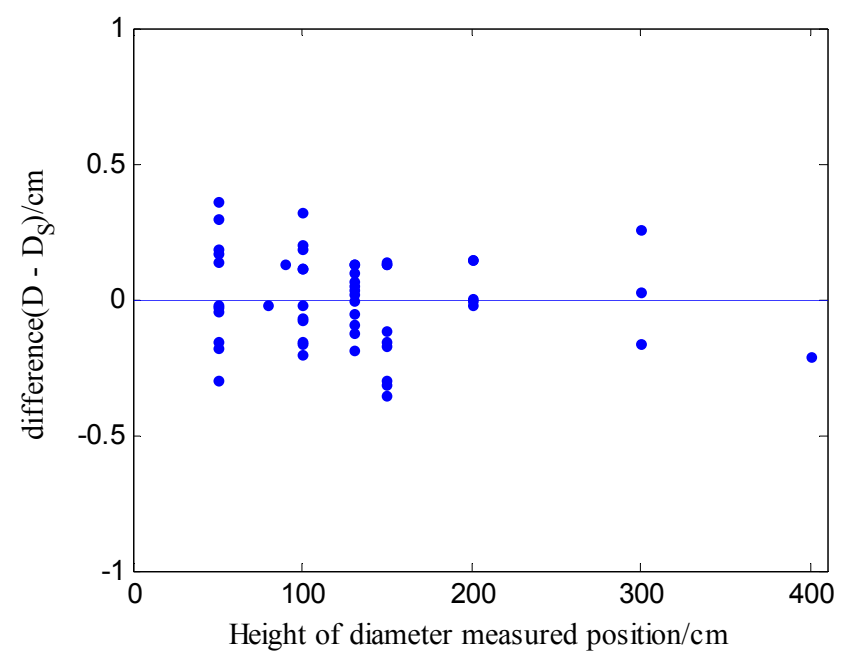

Figure 9. The relationship between the stem height and the diameter difference.

Although the method presented in this study yielded reasonable results, simulating the path of the diameter tape constructed by a cubic B-spline is challenging. Under artificial tension, there are no nonconvex sections that exist in the path of the diameter tape in the field work. However, the simulated path constructed by a cubic B-spline is not a global convex curve. Nonconvex sections are shown in Figure 10. Nonconvex sections are scattered along the curve. Compared with convex sections, nonconvex sections compose only a small portion of the curve. Because a nonconvex section can be regarded as a convex section when viewed from the opposite direction, these sections had a minor impact on stem diameter retrieval. The experimental results also support this conclusion.

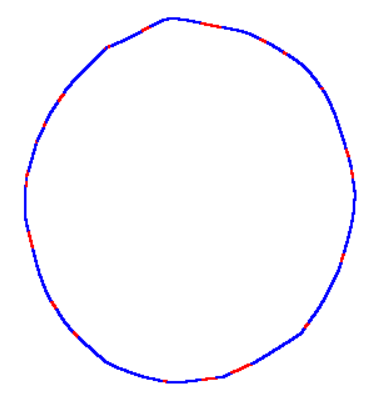

Figure 10. Nonconvex sections of the simulated path of the diameter tape constructed by a cubic B-spline. The red sections are nonconvex sections.

\section{Discussion}

Although the existing methods focused on deriving DBH, this study focused on obtaining the diameter at multiple heights of the stem. The calculation of the DBH is similar to the calculation of the diameter at multiple heights of the stem. Their difference is the height position of the diameter. 
No difference was observed in calculating the diameter after locating the stem cross-section. Thus, the results of the existing method can be compared with the results of this study.

\subsection{The Influence of Locating the Stem Cross-Section on Retrieving Stem Diameter}

In theory, stem diameter and the stem cross-section are closely related. The stem diameter has local characteristics. The diameters of different positions along the stem are not identical. Even for a stem segment with a length of less than $5 \mathrm{~cm}$, the difference in the diameter between the upper and the lower positions may be large. The points used to derive the stem diameter must be appropriately selected. In this study, the points used to derive the stem diameter were selected according to the cross-section and the width of the diameter tape. According to the experimental results, the accuracy of the circle fitting method was significantly improved. The maximum and minimum RMSE values of the circle fitting method, as listed in Table 1, were $4.2 \mathrm{~cm}$ and $1.8 \mathrm{~cm}$. The RMSE value of the circle fitting method using the points of this study was $0.7398 \mathrm{~cm}$. Compared with the RMSE value of the circle fitting method described in Table 1, the RMSE value of the circle fitting method using the points of this study was significantly less. The importance of stem cross-section location for retrieving stem diameter is illustrated.

\subsection{The Significance of Convex Hull Points for Retrieving Stem Diameter}

In the field work, stem diameter is determined at the bulgy part of the stem. However, the majority of the existing methods seem to disregard this fact. The accuracies of these methods are thus not guaranteed. The convex hull line method accounts for this issue. Compared with the circle fitting method, the RMSE value of the convex hull line was nearly one eighth the RMSE value of the circle fitting method, as shown in Figure 8. The accuracy of the diameter derived by the convex hull is significantly greater than that of the circle fitting method. The significance of the convex hull points for retrieving stem diameter is illustrated.

\subsection{Applicability of the Method to Forestry}

The path of the diameter tape is formed on the bulgy part of the stem cross-section. The bulgy part of the stem cross-section was reflected by the convex hull points of the stem cross-sectional points. Solving convex hull points of a given point cloud is a computation geometry problem. Once a point cloud is determined, the convex hull points of the point cloud are also determined. The main factors affecting the accuracy of stem diameter retrieval includes locating the stem cross-section and stem point set selection for retrieving stem diameter. In this study, the selection of the stem point set was based on the stem cross-section, and the thickness was the width of the diameter tape. Hence, stem diameter can be accurately retrieved from the stem cross-section. The procedure by which the stem cross-section was determined based on the relationships among the five geometric central points of the five successive stem slices. The iterative procedure can ensure the validity of the normal vector of the stem cross-sectional plane. The geometric central point of the stem slice was based on the convex hull points of the stem slice.

According to the above, the calculations in this study were based on the methodology of the field diameter measured by diameter tape and geometric computations. In fact, the stem point cloud is a version of a stem image. After a stem point cloud has been obtained and the profile of the stem has been reflected, the diameter can be obtained by the methods described in this study. The influences of the roughness of the stem bark, surface defects in the stem, the tilt degree of the stem and the height at the measured position were eliminated by the calculation of convex hull points and the iteration of the normal vector of the stem cross-sectional plane. Our findings were also supported by the experimental results. Similarly, the influence of the size of the stem diameter can also be eliminated. The maximum and minimum values of the stem diameter in this study were 57.4 and $2.7 \mathrm{~cm}$, respectively. Although a smaller and a larger stem were not included, the calculations used in this study, which are based on the geometric characteristics, ensure the validity of stem diameters retrieval for smaller stems and larger stems. 
The location of the cross-section is not considered in the existing methods. However, the convex hull line method is based on the convex hull points of the stem. The convex hull line does not meet the condition of geometry continuity. Thus, the accuracy of the existing methods is less than the accuracy of the method presented in this study.

\subsection{Future Work}

As described in Figure 10, the simulated path of diameter tape is a global convex curve. Construction of a closed smooth and global convex curve to simulate the path of diameter tape is recommended for future studies.

The thickness of the stem points used in calculations of stem diameter was equal to the width of the diameter tape. The width of a diameter tape is usually $1 \mathrm{~cm}$. The number of points is related to the density of the stem point cloud. When the density of the stem point cloud is sparse, the stem cross-section may not be reflected by the points with a thickness of $1 \mathrm{~cm}$. The method requires a dense stem point cloud. The appropriate density of the stem point cloud to facilitate deriving the diameter from the stem point cloud is an important topic for future research.

Although TLS is not an instrument for routine forest inventory yet, it can provide the geometrical structure of the trees. On the basis of these geometrical structures, accurate stem diameter, stem basal area and stem volume can be calculated using geometric computations and mathematics. The algorithm of this study was designed for retrieving stem diameters at multiple heights along the stem. Accurate calculation of the stem basal area and stem volume requires further research. Improving and applying the algorithm of this study to standing forests is another important topic for future research.

\section{Conclusions}

A novel algorithm for retrieving the stem diameter by simulating the path of the diameter tape is presented in this study. There are three steps in the algorithm: automatic determination of the stem cross-section at a given height along the stem; choice of the stem points from which to retrieve stem diameter and the simulation of the path of the diameter tape. Calculation of the algorithm based on the definition of stem diameter and obeying the diameter measurement rules in forest inventory. The experimental data were collected from different stem forms and tree species. Compared with the diameter measured in the field work, the RMSE values of circle fitting, convex hull line and simulating the path of diameter tape by the B-spline curve were $0.7398,0.1091$ and $0.0909 \mathrm{~cm}$, respectively. The importance of stem points' selection to retrieve the stem diameter and the applicability of the method were discussed.

The RMSE value of the method presented in this study satisfies the accuracy requirement in forest inventory. This study demonstrated that accurate determination of the stem cross-section is important for retrieving the stem diameter and that stem diameters retrieved from TLS can exhibit millimeter-level accuracy for individual trees. The study also describes the thickness of stem points needed to retrieve the stem diameter and provides an efficient and precise method for deriving the stem diameter from TLS data. Future studies should investigate the applicability of the algorithm to retrieving the stem diameter in forest stands.

Acknowledgments: This study was supported by the National High Technology Research and Development Program of China (No. 2012AA102002), the National Science and Technology Support Project of the Twelfth Five-Year Plan of China (No. 2012BAD22B02), the National Natural Science Foundation of China (No. 31470641, No. 61331018, No. 11501489 and No. 61572417), the Science and Technology Cooperation Project of He' nan Province and Academy (No. 122106000052), and the Nanhu Scholars Program of XYNU.

Author Contributions: Lei You collected and analyzed the data, designed and implemented the algorithm and prepared the manuscript. Shouzheng Tang provided valuable suggestions for the overall design of the study, especially regarding the forestry inventory, assisted with data collection and reviewed the manuscript. Xinyu Song secured funding for the project, reviewed the manuscript and polished the language of the manuscript. Yuancai Lei reviewed the manuscript and polished the language of the manuscript. Hao Zang, Minghua Lou and Chongyang Zhuang assisted with the data collection and the data pre-processing. 
Conflicts of Interest: The authors declare no conflict of interest.

\section{References}

1. Yang, B.; Dai, W.; Dong, Z.; Liu, Y. Automatic forest mapping at individual tree levels from terrestrial laser scanning point clouds with a hierarchical minimum cut method. Remote Sens. 2016, 8, 372. [CrossRef]

2. Olofsson, K.; Holmgren, J.; Olsson, H. Tree stem and height measurements using terrestrial laser scanning and the Ransac algorithm. Remote Sens. 2014, 6, 4323-4344. [CrossRef]

3. Srinivasan, S.; Popescu, S.C.; Eriksson, M.; Sheridan, R.D.; Ku, N.-W. Terrestrial laser scanning as an effective tool to retrieve tree level height, crown width, and stem diameter. Remote Sens. 2015, 7, 1877-1896. [CrossRef]

4. Liang, X.; Litkey, P.; Hyyppa, J.; Kaartinen, H.; Vastaranta, M.; Holopainen, M. Automatic stem mapping using single-scan terrestrial laser scanning. IEEE Trans. Geosci. Remote Sens. 2012, 50, 661-670. [CrossRef]

5. Liang, X.; Litkey, P.; Hyyppä, J.; Kaartinen, H.; Kukko, A.; Holopainen, M. Automatic plot-wise tree location mapping using single-scan terrestrial laser scanning. Photogramm. J. Finl. 2011, 22, 37-48.

6. Van Leeuwen, M.; Coops, N.C.; Newnham, G.J.; Hilker, T.; Culvenor, D.S.; Wulder, M.A. Stem detection and measuring DBH using terrestrial laser scanning. In Proceedings of the 2011 Silvilaser Conference, Hobart, Australia, 16-20 October 2011.

7. Király, G.; Brolly, G. Tree height estimation methods for terrestrial laser scanning in a forest reserve. Int. Arch. Photogramm. Remote Sens. Spat. Inf. Sci. 2007, 36, 211-215.

8. Simonse, M.; Aschoff, T.; Spiecker, H.; Thies, M. Automatic determination of forest inventory parameters using terrestrial laserscanning. In Proceedings of the Scandlaser Scientific Workshop on Airborne Laser Scanning of Forests, Umea, Sweden, 2-4 September 2003.

9. Maas, H.G.; Bienert, A.; Scheller, S.; Keane, E. Automatic forest inventory parameter determination from terrestrial laser scanner data. Int. J. Remote Sens. 2008, 29, 1579-1593. [CrossRef]

10. Gao, S. Branches Modeling and Morphological Parameters Extraction Technology Based on 3D Laser Scanning Technology; Chinese Academy of Forestry: Beijing, China, 2013.

11. Thies, M.; Pfeifer, N.; Winterhalder, D.; Gorte, B.G. Three-dimensional reconstruction of stems for assessment of taper, sweep and lean based on laser scanning of standing trees. Scand. J. For. Res. 2004, 19, 571-581. [CrossRef]

12. Tansey, K.; Selmes, N.; Anstee, A.; Tate, N.; Denniss, A. Estimating tree and stand variables in a corsican pine woodland from terrestrial laser scanner data. Int. J. Remote Sens. 2009, 30, 5195-5209. [CrossRef]

13. Aschoff, T.; Spiecker, H. Algorithms for the automatic detection of trees in laser scanner data. Int. Arch. Photogramm. Remote Sens. Spat. Inf. Sci. 2004, 36, 8-13.

14. Wezyk, P.; Koziol, K.; Glista, M.; Pierzchalski, M. Terrestrial laser scanning versus traditional forest inventory: First results from the polish forests. In Proceedings of the ISPRS Workshop on Laser Scanning, Espoo, Finland, 12-14 September 2007.

15. Hopkinson, C.; Chasmer, L.; Young-Pow, C.; Treitz, P. Assessing forest metrics with a ground-based scanning Lidar. Can. J. For. Res. 2004, 34, 573-583. [CrossRef]

16. Hess, C.; Bienert, A.; Härdtle, W.; Von Oheimb, G. Does tree architectural complexity influence the accuracy of wood volume estimates of single young trees by terrestrial laser scanning? Forests 2015, 6, 3847-3867. [CrossRef]

17. Nölke, N.; Fehrmann, L.; I Nengah, S.; Tiryana, T.; Seidel, D.; Kleinn, C. On the geometry and allometry of big-buttressed trees-A challenge for forest monitoring: New insights from 3D-modeling with terrestrial laser scanning. Biogeosci. For. 2015. [CrossRef]

18. Pueschel, P.; Newnham, G.; Rock, G.; Udelhoven, T.; Werner, W.; Hill, J. The influence of scan mode and circle fitting on tree stem detection, stem diameter and volume extraction from terrestrial laser scans. ISPRS J. Photogramm. Remote Sens. 2013, 77, 44-56. [CrossRef]

19. Yao, T.; Yang, X.; Zhao, F.; Wang, Z.; Zhang, Q.; Jupp, D.; Lovell, J.; Culvenor, D.; Newnham, G.; Ni-Meister, W. Measuring forest structure and biomass in new england forest stands using echidna ground-based Lidar. Remote Sens. Environ. 2011, 115, 2965-2974. [CrossRef]

20. Yu, X.; Liang, X.; Hyyppä, J.; Kankare, V.; Vastaranta, M.; Holopainen, M. Stem biomass estimation based on stem reconstruction from terrestrial laser scanning point clouds. Remote Sens. Lett. 2013, 4, 344-353. [CrossRef] 
21. Kankare, V.; Holopainen, M.; Vastaranta, M.; Puttonen, E.; Yu, X.; Hyyppä, J.; Vaaja, M.; Hyyppä, H.; Alho, P. Individual tree biomass estimation using terrestrial laser scanning. ISPRS J. Photogramm. Remote Sens. 2013, 75, 64-75. [CrossRef]

22. Hauglin, M.; Astrup, R.; Gobakken, T.; Næsset, E. Estimating single-tree branch biomass of norway spruce with terrestrial laser scanning using voxel-based and crown dimension features. Scand. J. For. Res. 2013, 28, 456-469. [CrossRef]

23. Calders, K.; Newnham, G.; Burt, A.; Murphy, S.; Raumonen, P.; Herold, M.; Culvenor, D.; Avitabile, V.; Disney, M.; Armston, J. Nondestructive estimates of above-ground biomass using terrestrial laser scanning. Methods Ecol. Evol. 2015, 6, 198-208. [CrossRef]

24. Morgenroth, J.; Gomez, C. Assessment of tree structure using a 3d image analysis technique-A proof of concept. Urban For. Urban Green. 2014, 13, 198-203. [CrossRef]

25. Liang, X.; Hyyppä, J.; Kankare, V.; Holopainen, M. Stem curve measurement using terrestrial laser scanning. In Proceedings of the 11th International Conference on LiDAR Applications for Assessing Forest Ecosystems, Hobart, Australia, 16-19 October 2011.

26. Kankare, V.; Liang, X.; Vastaranta, M.; Yu, X.; Holopainen, M.; Hyyppä, J. Diameter distribution estimation with laser scanning based multisource single tree inventory. ISPRS J. Photogramm. Remote Sens. 2015, 108, 161-171. [CrossRef]

27. Newnham, G.J.; Armston, J.D.; Calders, K.; Disney, M.I.; Lovell, J.L.; Schaaf, C.B.; Strahler, A.H.; Danson, F.M. Terrestrial laser scanning for plot-scale forest measurement. Curr. For. Rep. 2015, 1, 239-251. [CrossRef]

28. Pueschel, P. The influence of scanner parameters on the extraction of tree metrics from faro photon 120 terrestrial laser scans. ISPRS J. Photogramm. Remote Sens. 2013, 78, 58-68. [CrossRef]

29. Liang, X.; Hyyppä, J. Automatic stem mapping by merging several terrestrial laser scans at the feature and decision levels. Sensors 2013, 13, 1614-1634. [CrossRef] [PubMed]

30. West, P.W. Tree and Forest Measurement; Springer: Berlin, Germany, 2009.

31. Thies, M.; Spiecker, H. Evaluation and future prospects of terrestrial laser scanning for standardized forest inventories. Forest 2004, 2, 192-196.

32. McRoberts, R.E.; Chen, Q.; Domke, G.M.; Ståhl, G.; Saarela, S.; Westfall, J.A. Hybrid estimators for mean aboveground carbon per unit area. For. Ecol. Manag. 2016, 378, 44-56. [CrossRef]

33. De Berg, M.; van Kreveld, M.; Overmars, M.; Schwarzkopf, O.C. Computational Geometry; Springer: Berlin, Germany, 2000.

34. Piegl, L.; Tiller, W. The Nurbs Book; Springer: Berlin, Germany, 1997.

35. Lee, E.T. Choosing nodes in parametric curve interpolation. Comput. Aided Des. 1989, 21, 363-370. [CrossRef]

36. Rusu, R.B.; Cousins, S. 3D is here: Point cloud library (PCL). In Proceedings of the 2011 IEEE International Conference on Robotics and Automation (ICRA), Shanghai, China, 9-13 May 2011. 